\title{
Alluvial fan records from southeast Arabia reveal multiple windows for human dispersal
}

\section{SUPPLEMENTARY METHODS}

\section{Palaeoenvironmental Analyses}

Bulk geochemical analysis of elemental concentrations within the samples was determined by Inductively Coupled Plasma Atomic Emission Spectrometry (ICP-AES). Magnetic susceptibility values were determined using a Bartington MS2 sensor at 0.1 SI sensitivity, following the methods outlined by Dearing (1999). To determine grain size of the $<2 \mathrm{~mm}$ fraction, samples of air-dried sediment were gently disaggregated in de-ionised water and analysed using a Malvern Mastersizer 2000. Samples for bulk ( $<63 \mathrm{~mm}$ fraction) inorganic carbonate isotope analysis $\left({ }^{18} \mathrm{O}_{\text {carb }}\right.$ and $\left.{ }^{13} \mathrm{C}_{\mathrm{carb}}\right)$ were prepared following the procedure described by Lamb et al. (2000) and measurements made using a VG Optima mass spectrometer. Twelve sub-samples were prepared for phytolith analysis using the methods outlined in Parker et al. (2011). The phytoliths were compared with modern reference materials and by comparison with the phytolith key developed for southern Arabia based on approximately 500 taxa (Ball, 2002). The counting scheme was based on a modified version of Twiss et al. (1969), adapted further using Ball's (2002) classification of the southern Arabian flora. The D/P ratio represents the ratio of ligneous dicotyledon morphotypes (D) against Poaceae morphotypes (P), and is used as a proxy of the tree cover density (Alexandre et al., 1997). The climatic index (Ic\%) of Twiss (1987) indicates the influence of climate on the ratio of $\mathrm{C}_{3}$ to $\mathrm{C}_{4}$ morphotypes and has been used to imply cooler wet from warm dry conditions. The Iph(\%) aridity index (Diester-Haas et al., 1973) is a measure of mesic and xeric grassland conditions, with values greater than $35 \%$ associated with arid phases (as Parker et al., 2004).

\section{OSL Dating}

All samples were analysed at the Oxford Luminescence Dating (OLD) laboratory. Conventional sample preparation of $\mathrm{H}_{2} \mathrm{O}_{2}$ was followed to remove any organics, and $\mathrm{HCl}$ to remove carbonates. Samples were wet sieved to isolate the modal fraction, which was 180- $210 \mu \mathrm{m}$ in most cases, and 90-180 $\mu \mathrm{m}$ for samples OxL-1998, OxL-2093 and OxL2094. An etch using $40 \%$ HF for 45 minutes was used to remove feldspars and the alphairradiated rind of the quartz grains. Prepared quartz was mounted in $3 \mathrm{~mm}$ diameter aliquots onto aluminum discs with silicone oil. All samples were analyzed on a Risø TL- 
DA-15 automated luminescence reader, using blue LED stimulation and an EMI 9235QA photomultiplier protected by $6 \mathrm{~mm}$ of $\mathrm{U} 340$ filter.

\begin{tabular}{|c|c|c|c|c|c|c|c|c|c|c|c|c|}
\hline \multicolumn{5}{|c|}{ Sample details } & \multicolumn{5}{|c|}{ Dosimetry } & \multicolumn{3}{|c|}{$\mathrm{D}_{\mathrm{e}}$ calculation and age } \\
\hline 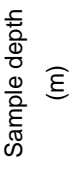 & 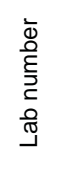 & 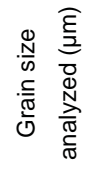 & 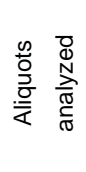 & 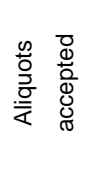 & $\mathrm{K}(\%)$ & Th (ppm) & $\mathrm{U}(\mathrm{ppm})$ & 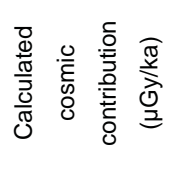 & 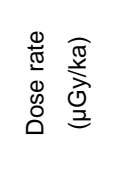 & $\begin{array}{l}\underset{0}{\mathbb{0}} \\
\stackrel{0}{0}\end{array}$ & 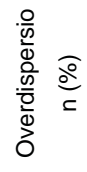 & $\begin{array}{l}\underset{\mathbb{x}}{x} \\
\frac{0}{0}\end{array}$ \\
\hline 2 & $\begin{array}{l}\text { OxL- } \\
2089\end{array}$ & $\begin{array}{l}180- \\
212\end{array}$ & 20 & 14 & $0.9 \pm 0.05$ & $1.27 \pm 0.13$ & $0.62 \pm 0.06$ & $0.16 \pm 0.014$ & $1.2 \pm 0.07$ & $0.65 \pm 0.11$ & 63 & $0.54 \pm 0.10$ \\
\hline 5.3 & $\begin{array}{l}\text { OxL- } \\
2090\end{array}$ & $\begin{array}{l}180- \\
212\end{array}$ & 20 & 20 & $0.75 \pm 0.04$ & $1.85 \pm 0.19$ & $0.9 \pm 0.09$ & $0.11 \pm 0.008$ & $1.11 \pm 0.06$ & $5.47 \pm 0.3$ & 24.7 & $4.9 \pm 0.38$ \\
\hline 8.3 & $\begin{array}{l}\text { OxL- } \\
2091\end{array}$ & $\begin{array}{l}180- \\
212\end{array}$ & 15 & 15 & $0.91 \pm 0.05$ & $1.14 \pm 0.11$ & $0.67 \pm 0.07$ & $0.078 \pm 0.006$ & $1.13 \pm 0.07$ & $82.5 \pm 6.7$ & 23.7 & $73 \pm 7.4$ \\
\hline 9.4 & $\begin{array}{l}\text { OxL- } \\
1996\end{array}$ & $\begin{array}{l}180- \\
212\end{array}$ & 21 & 21 & $0.83 \pm 0.04$ & $2.45 \pm 0.25$ & $0.94 \pm 0.09$ & $0.071 \pm 0.005$ & $1.2 \pm 0.07$ & $105.37 \pm 7.14$ & 27.1 & $88 \pm 7.8$ \\
\hline 17.4 & $\begin{array}{l}\text { OxL- } \\
2092\end{array}$ & $\begin{array}{l}180- \\
212\end{array}$ & 23 & 23 & $0.68 \pm 0.03$ & $1.05 \pm 0.11$ & $0.76 \pm 0.08$ & $0.035 \pm 0.003$ & $0.89 \pm 0.05$ & $115.8 \pm 12.87$ & 42.4 & $130 \pm 16.4$ \\
\hline 18.2 & $\begin{array}{l}\text { OxL- } \\
1997\end{array}$ & $\begin{array}{l}180- \\
212\end{array}$ & 21 & 19 & $0.82 \pm 0.04$ & $2.05 \pm 0.21$ & $0.84 \pm 0.08$ & $0.033 \pm 0.002$ & $1.1 \pm 0.07$ & $161.9 \pm 14.88$ & 32 & $147 \pm 16.2$ \\
\hline 23.4 & $\begin{array}{l}\text { OxL- } \\
2093\end{array}$ & $90-180$ & 16 & 16 & $0.68 \pm 0.03$ & $1.35 \pm 0.14$ & $0.9 \pm 0.09$ & $0.024 \pm 0.002$ & $0.95 \pm 0.06$ & $142.89 \pm 12.86$ & 32.6 & $151 \pm 16.4$ \\
\hline 28 & $\begin{array}{l}\text { OxL- } \\
2094\end{array}$ & $90-180$ & 14 & 14 & $0.9 \pm 0.05$ & $1.29 \pm 0.13$ & $0.7 \pm 0.07$ & $0.018 \pm 0.001$ & $1.1 \pm 0.07$ & $174.15 \pm 12.34$ & 18.9 & $159 \pm 15.2$ \\
\hline 29.6 & $\begin{array}{l}\text { OxL- } \\
2095\end{array}$ & $\begin{array}{l}180- \\
212\end{array}$ & 15 & 13 & $0.89 \pm 0.04$ & $2.01 \pm 0.2$ & $0.85 \pm 0.09$ & $0.017 \pm 0.001$ & $1.15 \pm 0.07$ & $180.04 \pm 17.48$ & 26.6 & $157 \pm 18.0$ \\
\hline 32.1 & $\begin{array}{l}\text { OxL- } \\
1998\end{array}$ & $\begin{array}{l}180- \\
212\end{array}$ & 18 & 17 & $0.68 \pm 0.03$ & $1.75 \pm 0.18$ & $0.95 \pm 0.1$ & $0.014 \pm 0.001$ & $0.96 \pm 0.06$ & $153.94 \pm 8.55$ & 10.2 & $160 \pm 13.1$ \\
\hline 33.7 & $\begin{array}{l}\text { OxL- } \\
2096\end{array}$ & $90-180$ & 16 & 16 & $0.44 \pm 0.02$ & $1.26 \pm 0.13$ & $0.85 \pm 0.09$ & $0.013 \pm 0.001$ & $0.7 \pm 0.04$ & $124.49 \pm 15.53$ & 48.3 & $179 \pm 24.7$ \\
\hline 39.4 & $\begin{array}{l}\text { OxL- } \\
2097\end{array}$ & $\begin{array}{l}180- \\
212\end{array}$ & 17 & 16 & $0.47 \pm 0.02$ & $1.05 \pm 0.11$ & $0.85 \pm 0.09$ & $0.01 \pm 0.001$ & $0.7 \pm 0.04$ & $109.76 \pm 11.81$ & 38.2 & $158 \pm 19.5$ \\
\hline
\end{tabular}

Supplementary Table DR1: Full details of OSL results obtained from Al Sibetah

Dosimetry for all samples was provided by Inductively-Coupled Plasma Mass (or Atomic Emission) Spectrometry (ICP-MS/-AES) on subsamples of the material collected for dating. Moisture content was assumed to be $5 \pm 2 \%$ for all samples, which at 2 sigma results in a range (1-9\%) typically observed for arid-zone sediment (e.g. Stokes et al., 1997; Telfer and Thomas, 2007). The cosmic ray contributions were calculated using the formula of Prescott and Hutton (1994). Prepared quartz was measured with the standard Single Aliquot Regeneration (SAR) protocol of Murray and Wintle (2000; 2003), using a 10 Gy test dose, and the post- IR blue feldspar contamination test of Duller (2003).

Preheats of $240{ }^{\circ} \mathrm{C}$ for 10 seconds for natural and regenerated $\left(L_{x}\right)$ measurements, and 220 ${ }^{\circ} \mathrm{C}$ for 10 seconds for test dose $\left(\mathrm{T}_{\mathrm{x}}\right)$ measurements, were used throughout. All OSL measurements were made at $130{ }^{\circ} \mathrm{C}$. Aliquots failing IR-contamination (at $\pm 5 \%$ ), recycling ratio (at $\pm 5 \%$ ) or recuperation tests were very scarce (a total of twelve aliquots rejected from a total of 216 analyzed), and were rejected from further analysis. Of these aliquots failing quality assurance tests, six came from the shallowest sample, which had an 
Equivalent Dose $\left(D_{e}\right)$ below $1 \mathrm{~Gy}$, and were due to the IR-depletion test ratio being elevated slightly above unity.

\section{SUPPLEMENTARY RESULTS}

\section{Phytolith Analyses}

Palaeosols display a lack of well defined horizons, indicative of continual sedimentation and in keeping with the steady waning of stream flow. A lack of current ripple laminations preclude these fines as splay deposits (e.g. Nichols \& Fisher, 2007). A profuse distribution of root networks within palaeosols is characteristic of grassland development (Retallack, 1991). Overall phytolith counts were generally low from MIS 6-age palaeosols (Supplementary Table DR2), however, grassland was the dominant vegetation type, with a mix of $\mathrm{C}_{3}$ and $\mathrm{C}_{4}$ morphotypes. $\mathrm{C}_{3}$ Pooid phytolith morphotypes accounted for between $27 \%$ and 60\%, whilst Panicoid and Chloridoid values range between 4.7-10\% and 3-10\% respectively. Sedges occurred in all samples but in low values, except in AP4 \& AP5 (main text, Figure 2), where values were over $6 \%$ of the total sum. Circular rugose morphoytpes derived from woody Ligneous Dicotyledon were also present but in low numbers. The lowest sample from the sequence examined had $8.4 \%$ of Lig. Dicot. forms present. Other values from MIS 6 palaeosols accounted from 1.5 to 3\% except AP4, where no circular rugose forms were observed. Phytolith $\mathrm{D} / \mathrm{P}$ values fall rapidly from 0.18 at the base of the sequence (AP1) to 0.03 at $32.0 \mathrm{~m}$ (AP3), before falling to zero in AP4. Values remain low but rise to 0.18 during MIS 5a. Iph\% values are variable throughout the entire sequence, ranging from 60-25\% during MIS 6, and 55.07-29.41 during MIS 5. Ic\% values indicate mixed but largely mesic $\mathrm{C}_{3}$ and $\mathrm{C}_{4}$ grasslands during MIS 6, with more xeric conditions observed within the upper two MIS 6 palaeosols (AP5 \& AP6). Pooid phytolith morphotypes are common during MIS 5 soil development phases, accounting for 23-55\% of the total sum, while Paniocoid types are present throughout with higher values (10\%) during MIS 5e. Chloridoid types comprise $4 \%$ in three of the MIS 5 samples, except for AP8 (MIS 5c) where the values rise to $12.03 \%$. D/P values are notably higher in AP7 \& AP9 (MIS5 e and MIS 5a respectively), indicating an increased proportion of woody taxa in the region during these times, relative to MIS 5c. A similar pattern is observed in Ic\% values, where more mesic conditions are recorded in MIS 5e and 5a palaeosols, and more xeric conditions during MIS 5c. 


\begin{tabular}{|c|c|c|c|c|c|c|c|c|c|c|c|c|c|c|c|}
\hline 동 & ह & 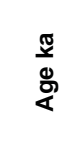 & 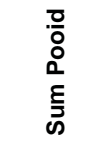 & 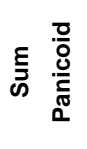 & E $\frac{\text { 윽 }}{\text { के }}$ & 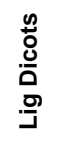 & 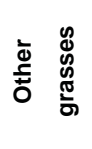 & 잉 & $\begin{array}{l}0 \\
\mathbb{J} \\
\frac{\pi}{\pi} \\
\frac{\pi}{ \pm 0} \\
\frac{0}{4}\end{array}$ & 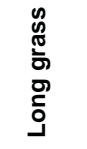 & 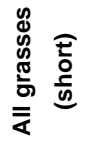 & 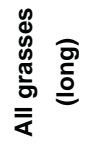 & $\frac{n}{a}$ & $\begin{array}{l}\stackrel{\circ}{\circ} \\
\text { 응 }\end{array}$ & 응 \\
\hline 9.4 & 357 & 88 & 30.81 & 3.64 & 3.92 & 8.96 & 10.92 & 4.48 & 0.00 & 7.00 & 49.30 & 17.24 & 0.18 & 51.85 & 80.29 \\
\hline 13.0 & 334 & & 23.42 & 9.81 & 12.03 & 3.80 & 1.27 & 1.90 & 0.00 & 20.25 & 46.52 & 15.20 & 0.08 & 55.07 & 51.75 \\
\hline 15.6 & 579 & & 36.44 & 10.36 & 4.32 & 7.77 & 8.98 & 4.32 & 0.69 & 9.33 & 60.10 & 10.83 & 0.13 & 29.41 & 71.28 \\
\hline 16.2 & 462 & 130 & 54.76 & 4.98 & 4.76 & 4.11 & 11.69 & 1.52 & 0.43 & 3.68 & 76.19 & 11.19 & 0.05 & 48.89 & 84.90 \\
\hline 18.3 & 174 & 147 & 27.59 & 8.62 & 6.90 & 2.30 & 18.97 & 2.30 & 0.00 & 14.94 & 62.07 & 27.68 & 0.04 & 44.44 & 64.00 \\
\hline 20.2 & $90^{*}$ & & 31.11 & 8.89 & 10.00 & 3.33 & 11.11 & 2.22 & 0.00 & 6.67 & 61.11 & 10.14 & 0.05 & 52.94 & 62.22 \\
\hline 23.6 & $135^{\star}$ & 151 & 28.15 & 4.44 & 6.67 & 1.48 & 14.07 & 6.67 & 0.74 & 9.63 & 53.33 & 12.20 & 0.03 & 60.00 & 71.70 \\
\hline 27.7 & $30^{*}$ & 159 & 60.00 & 10.00 & 3.33 & 0.00 & 3.33 & 3.33 & 0.00 & 10.00 & 76.67 & 0.00 & 0.00 & 25.00 & 81.82 \\
\hline 30.2 & $107^{*}$ & 157 & 38.32 & 4.67 & 4.67 & 4.67 & 3.74 & 7.48 & 0.00 & 9.35 & 51.40 & 5.13 & 0.09 & 50.00 & 80.39 \\
\hline 32.0 & $162^{*}$ & & 41.98 & 9.88 & 8.64 & 1.85 & 13.58 & 3.70 & 0.00 & 6.17 & 74.07 & 8.33 & 0.03 & 46.67 & 69.39 \\
\hline 33.8 & $101^{*}$ & 160 & 28.71 & 7.92 & 2.97 & 3.96 & 20.79 & 0.99 & 0.99 & 8.91 & 60.40 & 0.00 & 0.07 & 27.27 & 72.50 \\
\hline 39.4 & $133^{*}$ & 158 & 27.27 & 6.99 & 8.39 & 8.39 & 4.20 & 2.80 & 0.00 & 11.19 & 46.85 & 7.42 & 0.18 & 54.55 & 63.93 \\
\hline
\end{tabular}

Supplementary Table DR2: Summary of phytolith results from Al Sibetah (*denotes samples with statistically low counts)

\section{Chronology}

At least thirteen aliquots were used to provide estimates of De for each sample, with further aliquots used for Dose Recovery Tests (DRTs) on seven samples. All samples recovered a known dose, of a size approximately equal to the natural burial dose, to within $\pm 10 \%$, and generally within $\pm 5 \%$. Overall, for 24 DRTs on seven samples, the mean recovery ratio was $1.04 \pm 0.06$. The Central Age Model of Galbraith et al (1999) was used to derive a single De estimate from the replicate measurements; the justification of this choice is given more fully in the Chronology of section 2 of this Supplementary Information. Full details of the OSL results are given in Table DR1, and the stratigraphic relationship with age, examples of $D_{e}$ distributions and sample growth are shown in Figure DR1. The interbedded nature of the sequence meant that samples could not be obtained from gravel-rich units. Thus samples were retrieved from strata considered to be suitably rich in sand-sized quartz and where possible, at intervals which would yield important information regarding the timing of landscape changes. Of the 12 dates, a total of 4 were retrieved from predominantly coarse sand-rich strata, whilst 8 were retrieved from silt/sand and palaeosol strata. Some of the samples analysed had relatively high overdispersion values (sensu Galbriath et al., 1999), implying variance in the distribution of the De values beyond that which might be expected from their individual precisions. 
a)

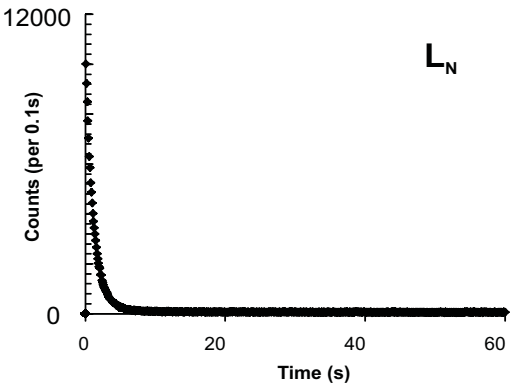

c)

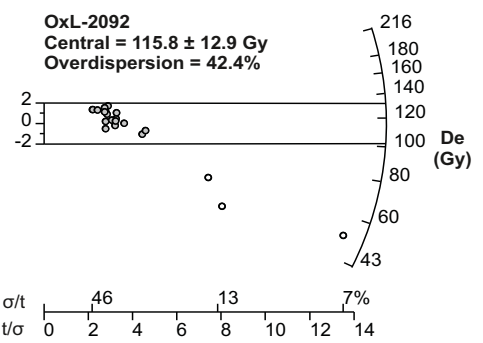

b)

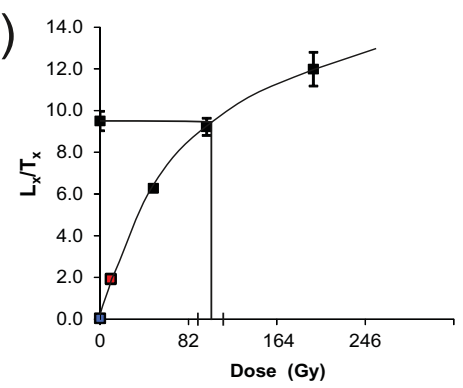

d)

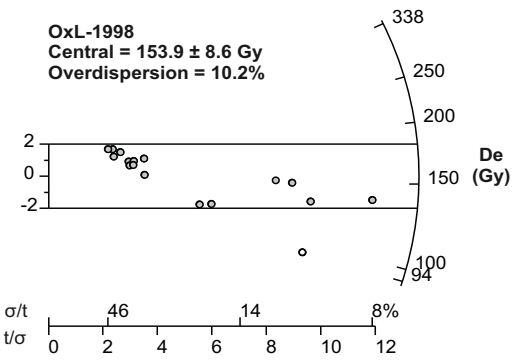

e)

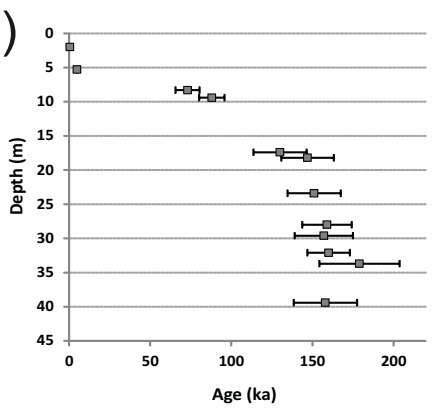

Supplementary Figure DR1: Figure showing a) example decay curve of natural OSL $\left(\mathrm{L}_{\mathrm{N}}\right)$ as a function of illumination time, b) example OSL dose response curve from sample OxL-2091, c \& d) radial plots for the De distribution analysis of samples OxL-2092 and OxL-1998 respectively, and e) the stratigraphic relationship of all age samples.

Excluding the uppermost unit, which had a high overdispersion but a $\mathrm{D}_{\mathrm{e}}$ of less than $1 \mathrm{~Gy}$, overdispersion for the other units ranges from $10-48 \%$. Values of less than 20 $\%$ are often (Arnold and Roberts, 2009) used to infer well-bleached conditions, and assumptions about the bleaching characteristics at the time of deposition may influence the choice of the most appropriate age model with which to derive a single $\mathrm{D}_{\mathrm{e}}$ estimate (Arnold et al., 2007). In this instance, we argue in favor of the Central Age Model of Galbraith et al. (1999) to derive all single De estimate from the replicate measurements, on stratigraphical and sedimentological grounds. Bleaching of samples, especially in fluvial environments, must be questioned, and might argue in favor of De estimations methods favoring minimum age estimation (Rittenour 2008). However, overdispersion may also be due to a number of other factors, including micro-scale variation in the beta radiation field 
and bioturbation, which are non-systematic in nature and thus argue in favor of central tendency estimates.

The dose distributions for all samples are non-skewed and do not show the typical (though not inevitable) positive skew associated with partial bleaching. The majority of samples do not show very high overdispersions (only three exceed $40 \%$, of which one is the uppermost sample - OxL2089 - with a $D_{e}$ of $<1 \mathrm{~Gy}$ ), which is within the range observed from desert dune sand samples which are known to be well-bleached (Lomax et al., 2007). The two deep samples yielding the highest overdispersions (42\% and 48\%) are from samples which are, respectively, sampled from sands within a gravelly conglomeritic layer (in which ophiolitic clasts, likely to be relatively enriched in uranium and thorium, are abundant) and from a thin sand/silt palaeosol between two massive conglomeritic units. Furthermore, in the palaeosol units, evidence of bioturbation in the form of root development is abundant. Lastly, and crucially, two of the deeper samples (OxL-2094 and OxL-1998) yielded overdispersions (18\% and 10\% respectively) indicating homogenous populations, for which models of central tendency are clearly preferable to minimum age models. Application of Bayesian reasoning suggests that these might be used as constraints, and indeed, if minimum age methods are used for the surrounding samples, significant age inversions become abundant in the age depth model. The CAM-derived ages from Al Sibetah are, within errors, in stratigraphic order. The effects of erosion and lacunae in sediment deposition mean that it is highly unlikely that sedimentation between each date was continuous, however, each date provides an important age-marker for phases of climatically-induced landscape change. It is reasonable to assume that during arid periods, the activation of fan drainage systems and palaeosol formation did not occur and that as such, the dated accumulation of gravels and palaeosols is directly representative of increased precipitation/humidity within the region.

\section{REFERENCES}

Alexandre, A., Meunier, J.D., Lezine, A.M., Vincens, A., and Schwartz, D., 1997, Phytoliths: indicators of grassland dynamics during the late Holocene in intertropical Africa: Palaeogeography, Palaeoclimatology, Palaeoecology 136, 213-229, doi:0.1016/S0031-0182(97)00089-8.

Arnold, L.J., Bailey, R.M., and Tucker, G.E., 2007, Statistical treatment of fluvial dose distributions from southern Colorado arroyo deposits: Quaternary Geochronology, v. 2, p. 162-167, doi:10.1016/j.quageo.2006.05.003

Arnold, L.J., and Roberts, R.G., 2009. Stochastic modelling of multi-grain equivalent dose 
(D-e) distributions: Implications for OSL dating of sediment mixtures:

Quaternary Geochronology, v. 4, p. 204-230, doi:10.1016/j.quageo.20 08.12.0.01

Ball, T.B., 2002, Phytoliths of Dhofar, Oman, Arabia: Brigham Young University, Utah, CD-ROM.

Dearing, J., 1999, Magnetic susceptibility, in Walden, J., Oldfield, F., and Smith, J., eds., Environmental Magnetism: a Practical Guide. Quaternary Research Association, London, p. 35-63.

Diester-Haass L., Schrader H.-J., and Thiede J., 1973, Sedimentological and paleoclimatological investigations of two pelagic ooze cores off Cape Barbas, North-West Africa: Meteor Forschungsergebnisse, Deutsche Forschungsgemeinschaft, Reihe C Geologie und Geophysik, Gebrüder Bornträger, Berlin, Stuttgart, C16, p. 19-66, doi:10.1594/PANGAEA.548418

Duller, G.A.T., 2003, Distinguishing quartz and feldspar in single grain luminescence measurements: Radiation Measurements, v. 37, p. 161-165, doi:10.1016/S1350-4487(02)00170-1

Galbraith, R.F., Roberts, R.G., Laslett, G.M., Yoshida, H., and Olley, J.M., 1999. Optical dating of single and multiple grains of quartz from Jinmium rock shelter, northern Australia, part 1, Experimental design and statistical models: Archaeometry 41, 339-364, doi:10.1111/j.1475-4754.1999.tb00987.x

Lamb, A.L., Leng, M.J., Lamb, H.F., and Mohammed, M.U., 2000, A 9000-year oxygen and carbon isotope record of hydrological change in a small Ethiopian crater lake: The Holocene, v. 10, p. 167-177, doi: 10.1191/095968300677444611

Lomax, J., Hilgers, A., Twidale, C.R., Bourne, J.A., and Radtke, U., 2007, Treatment of broad palaeodose distributions in OSL dating of dune sands from the western Murray Basin, South Australia: Quaternary Geochronology, v. 2, p. 51-56, doi:10.1016/j.quageo.2006.05.015.

Murray, A.S., and Wintle, A.G., 2000, Luminescence dating of quartz using an improved single-aliquot regenerative-dose protocol: Radiation Measurements, v. 32, p. 57-73, doi: 10.1016/S1350-4487(99)00253-X

Murray, A.S., and Wintle, A.G., 2003, The single aliquot regenerative dose protocol: potential for improvements in reliability: Radiation Measurements, v. 37, p. 377-381, doi:10.1016/S1350-4487(03)00053-2.

Nichols, G.J., and Fisher, J.A., 2007, Processes, facies and architecture of fluvial distributary system deposits: Sedimentary Geology, v. 195, p. 75-90, doi:10.1016/j.sedgeo.2006.07.004. 
Parker, A. G., Eckersley, L., Smith, M. M., Goudie, A. S., Stokes, S., Ward, S., White, K., and Hodson, M.J., 2004, Holocene vegetation dynamics in the northeastern Rub' alKhali desert, Arabian Peninsula: a phytolith, pollen and carbon isotope study: Journal of Quaternary Science, v. 19, no. 7, p. 665-676, doi:10.1002/jqs.880.

Parker, A. G., Lee-Thorp, J., and Mitchell, P. J., 2011, Late Holocene Neoglacial conditions from the Lesotho highlands, southern Africa: phytolith and stable carbon isotope evidence from the archaeological site of Likoaeng: Proceedings of the Geologists' Association, v. 122, p. 201-211, doi:10.1016/j.pgeola.2010.09.005

Prescott, J. R., and Hutton, J. T., 1994, Cosmic ray contributions to dose rates for luminescence and ESR dating: large depths and long-term time variations: Radiation Measurements, v. 23, p. 497-500, doi:10.1016/1350-4487(94)90086-8

Retallack, G.J., 1991, Untangling the effects of burial alteration and ancient soil formation: Annual Review of Earth Planetary Sciences, v. 19, p. 183-206, doi:10.1146/annurev.ea.19.050191.001151

Rittenour, T.M., 2008, Luminescence dating of fluvial deposits: applications to geomorphic, palaeoseismic and archaeological research: Boreas, v. 37, p.613635, doi:10.1111/j.1502-3885.2008.00056.x.

Stokes, S., Haynes., G., Thomas, D.S.G., Horrocks, J.L., Higginson, M., and Malifa, M., 1997, Punctuated aridity in southern Africa during the last glacial cycle: The chronology of linear dune construction in the northeastern Kalahari: Palaeogoegraphy, Palaeoclimatology, Palaeoecology, v. 137, p. 305-322, doi:10.1016/S0031-0182(97)00106-5

Telfer, M.W., and Thomas, D.S.G., 2007, Late Quaternary linear dune accumulation and chronostratigraphy of the southwestern Kalahari: implications for aeolian palaeoclimatic reconstructions and predictions of future dynamics: Quaternary Science Reviews, v. 26, p. 2617-2630, doi: 10.1016/j.quascirev.2007.07.006.

Theunissen, J.D., 1994, A method for isolating and preparing silica bodies in grasses for scanning electron microscopy: Biotechnic and Histochemistry, v. 69, p. 291-294, doi:10.3109/10520299409106305

Twiss, P.C., 1987, Grass-opal phytoliths as climatic indicators of the Great Plains Pleistocene: Kansas Geological Survey Guidebook Series, v. 5, p. 179-185.

Twiss, P.C., Suess, E., Smith, R.M., 1969, Morphological classification of grass phytoliths: Soil Science Society of America: Proceedings v. 33, p. 109-115. 